\title{
Effect of noncovalent interaction on the self- assembly of a designed peptide and its potential use as a carrier for controlled bFGF release
}

This article was published in the following Dove Press journal:

International Journal of Nanomedicine

18 January 2017

Number of times this article has been viewed

Yanfei Liu

Ling Zhang

Wei Wei

Key Laboratory of Cell Engineering of Guizhou Province, Affiliated Hospital of Zunyi Medical College, Zunyi,

Guizhou, People's Republic of China
Abstract: Peptide self-assembly is one of the promising bottom-up approaches for creating synthetic supermolecular architectures. Noncovalent interactions such as hydrophobic packing, electrostatic interaction, and polypeptide chain entropy $\left(\Delta S_{\mathrm{C}}\right)$ are the most relevant factors that affect the folding and self-assembly of peptides and the stability of supermolecular structures. The GVGV tetrapeptide is an abundant repeat in elastin, an extracellular matrix protein. In this study, four GVGV-containing peptides were designed with the aim of understanding the effects of these weak interactions on peptide self-assembly. Transmission electron microscopy, circular dichroism spectroscopy, dynamic light scattering measurements, and rheometry assays were used to study the structural features of the peptides. Because self-assembling peptides with different amino acid sequences may significantly affect protein release, basic fibroblast growth factor (bFGF) was used as a model molecule and encapsulated within the P2 (RLDLGVGVRLDLGVGV) hydrogel to study the release kinetics. The results showed that the balance among hydrophobic effects, electrostatic interactions, and chain entropy determined the molecular state and self-assembly of the peptide. Moreover, encapsulation of bFGF within the P2 hydrogel allowed its sustained release without causing changes in the secondary structure. The release profiles could be tuned by adjusting the $\mathrm{P} 2$ hydrogel concentration. Cell Counting Kit- 8 and Western blot assays demonstrated that the encapsulated and released bFGFs were biologically active and capable of promoting the proliferation of murine fibroblast NIH-3T3 cells, most likely due to the activation of downstream signaling pathways.

Keywords: peptide self-assembly, hydrogel, noncovalent interaction, growth factor delivery, proliferation, signaling pathways

\section{Introduction}

Molecular self-assembly is a powerful approach for fabricating the sophisticated structures and materials from the bottom up. ${ }^{1}$ Inspired by nature, a variety of biomolecules, including amino acids, ${ }^{2-4}$ peptides,${ }^{5-8}$ proteins,${ }^{9,10}$ DNA,${ }^{11}$ saccharides, ${ }^{12}$ lipids,${ }^{13,14}$ and their derivatives, ${ }^{15-17}$ have been used as versatile building blocks for the design of functional structures at the nanoscale and microscale through molecular self-assembly. Building blocks have unique physical and chemical properties, which, if harnessed effectively, can result in materials with highly functional characteristics.

Recently, peptide-based self-assembling materials have gained much attention in several fields for their diverse applications such as drug/protein release, ${ }^{18,19}$ regenerative medicine and tissue engineering, ${ }^{20-23}$ three-dimensional (3D) cell culture, ${ }^{24,25}$ and nanotechnology, ${ }^{26}$ because their characteristics mimic the $3 \mathrm{D}$ structures of the extracellular matrix (ECM). Generally, these systems involve designing a peptide 
monomer consisting of a structural motif that folds to adopt a known secondary structure such as the $\alpha$-helix, ${ }^{15,27}$ $\beta$-strand, ${ }^{8,23}$ and $\beta$-hairpin. ${ }^{7,19}$ Noncovalent interactions, including hydrophobic, hydrophilic, $\pi$-stacking, hydrogen bonding, and polypeptide chain entropy $\left(\Delta S_{\mathrm{C}}\right)$, play important roles in triggering the assembly of peptide nanostructures. ${ }^{28}$ It is still a challenge for scientists and engineers to incorporate these interactions into the fabrication of functional peptide-based materials.

The 16-residue peptide RADARADARADARADA (RADA16-I) is an ionic self-complementary peptide consisting of four repeats of a four-amino acid sequence: hydrophobic-positively charged-hydrophobic-negatively charged. ${ }^{8}$ This peptide can undergo spontaneous assembly into well-organized nanofibers and further forms scaffolds with pore sizes between 5 and $200 \mathrm{~nm} .{ }^{29}$ The scaffold has a similar physical structure to the natural ECM and has been used in several applications, including 3D cell culture, tissue recovery, and controlled protein release. To date, although the self-assembly dynamics of RADA16-I are quite clear, a comprehensive understanding is lacking about the effects of amino acid sequences and noncovalent intermolecular interactions on peptide self-assembly.

The GVGV tetrapeptide is an abundant repeat in elastin, an ECM protein that is responsible for the elastic and extensibility properties of vertebrate tissues. These GVGV repeats constitute the hydrophobic domain of tropoelastin, the monomeric precursor of elastin, whereas the hydrophobic domains confer properties of self-assembly and extensibility. ${ }^{30}$ Poly-(GVGV), poly-(GVGVA), and poly-(GGVGV) are ambivalent sequences that form amyloid fibers under certain conditions, ${ }^{31}$ whereas poly-(GVGVP) adopts a $\beta$-sheet structure in the folded state and can be used as building blocks to create elastin-like polypeptides (ELPs) ${ }^{32,33}$ and silk-elastinlike protein polymers (SELPs). ${ }^{34,35}$ In this study, the GVGV tetrapeptide was incorporated into the RADA16-I sequence to evaluate the effects of weak interactions on the folding and self-assembly of the peptide. Figure 1 shows the amino acid sequences of these peptides, which have different peptide chain entropies, charge distributions, and hydrophobic driving<smiles>CC(=O)NC(CCCNC(=N)N)C(=O)NC(C)C(=O)NC(CC(=O)O)C(=O)NC(C)C(=O)NCC(=O)NC(C(=O)NCC(=O)NC(C(N)=O)C(C)C)C(C)C</smiles>

P1: RADAGVGVRADAGVGV

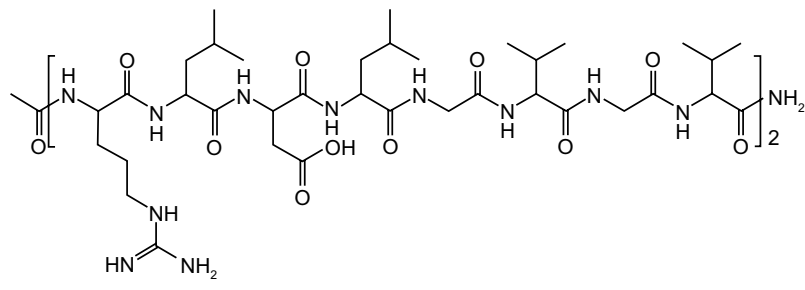

P2: RLDLGVGVRLDLGVGV<smiles>CC(=O)CC(NC(=O)C(NC(=O)CNC(=O)C(NC(=O)CNC(=O)C(C)NC(=O)C(CCCN)NC(=O)C(C)NC(=O)C(CCCN)NC(C)=O)C(C)C)C(C)C)C(=O)NC(C)C(=O)NC(CC(=O)O)C(=O)NC(C)C(=O)NCC(=O)NC(C(=O)NCC(=O)NC(C(N)=O)C(C)C)C(C)C</smiles>

P3: RARAGVGVDADAGVGV<smiles>CC(=O)CC(NC(=O)C(CC(C)C)NC(=O)CNC(=O)C(NC(=O)CNC(=O)C(CC(C)C)NC(=O)C(CCCN)NC(=O)C(CC(C)C)NC(=O)C(CCCN)NC(C)=O)C(C)C)C(=O)NC(CC(=O)O)C(=O)NC(CC(C)C)C(=O)NC(CC(C)C)C(=O)NCC(=O)NC(C(=O)NCC(=O)NC(C(N)=O)C(C)C)C(C)C</smiles><smiles>N=C(N)NC(=N)N</smiles>

P4: RLRLGVGVDLDLGVGV 
forces for self-assembly and peptide chain entropies. Generally, two RADA repeat sequences of RADA16-I were replaced by two GVGV to increase the peptide chain entropy (P1 [RADAGVGVRADAGVGV]). We also increased the hydrophobic nature of the P1 molecule by using leucine (L) instead of alanine (A; P2 [RLDLGVGVRLDLGVGV]). Finally, we changed the charge distribution pattern of the peptides by swapping the charged amino acids (P3 [RARAGVGVDADAGVGV] and P4 [RLRLGVGVDLDLGVGV]) to study the effects of the intramolecular electrostatic interaction on peptide selfassembly.

The goal of this study was to develop biomaterials that can undergo in situ gelation; thus, we evaluated the possibility that GVGV-containing peptides may be able to serve as potential carriers for the controlled release of drugs or growth factors. To this end, basic fibroblast growth factor (bFGF) was chosen and encapsulated within the designed peptide hydrogel to study the release kinetics. In addition, the effects of this controlled released system on cell proliferation and the possible underlying mechanisms were also investigated.

\section{Materials and methods Peptide design and synthesis}

All the peptides (P1-P4, purity 95\%) were commercially synthesized by GL Biochem (Shanghai) Ltd (Shanghai, People's Republic of China), stored at $-20^{\circ} \mathrm{C}$, and used without further purification. The $\mathrm{N}$ - and $\mathrm{C}$-termini of these peptides were protected by acetylation and amidation, respectively. Stock solutions of peptides were prepared in sterile water and stored at $4^{\circ} \mathrm{C}$ before use.

\section{Preparation of $\mathrm{P} 2$ hydrogel}

For the preparation of the P2 hydrogel, the P2 stock solution was diluted to a desired concentration. Self-assembly of P2 was triggered with the addition of an equal volume of phosphate buffer ( $\mathrm{pH}$ 7.2) or cell growth medium ( $\mathrm{pH}$ 7.4) without fetal bovine serum (FBS), followed by $30 \mathrm{~min}$ of incubation to allow the hydrogel formation.

\section{Transmission electron microscopy (TEM) measurement}

For TEM examinations, the peptide stocks were diluted to $0.05 \%$ weight/volume (wt/vol) and incubated overnight at room temperature. Before observation, $5 \mu \mathrm{L}$ of peptide solution was dropped on the surface of a copper grid covered by a perforated formvar film and negatively stained with $1 \%$ phosphotungstic acid. After drying in air for a few minutes, the grid was observed directly under the transmission electron microscope (H-7650; Hitachi, Tokyo, Japan).

\section{Dynamic light scattering (DLS) measurement}

Size distributions of nanostructures formed by the peptides were measured by using a Zetasizer Nano ZS instrument (Nano ZS90; Malvern Instruments, Malvern, UK). All the peptides were diluted to $0.05 \% \mathrm{wt} / \mathrm{vol}$ and sonicated for $15 \mathrm{~min}$ to break the weak interactions, followed by standing at room temperature for $4 \mathrm{~h}$ before measurements. For each sample, $1 \mathrm{~mL}$ of the peptide solution was added into a low-volume disposable cuvette and kept at equilibrium at $25^{\circ} \mathrm{C}$ for $3 \mathrm{~min}$ prior to measurement. Intensity data from each sample were recorded, and size-versus-fraction distribution plot was obtained.

\section{Circular dichroism (CD) spectroscopy}

Stock solutions of the peptides were diluted to $0.025 \% \mathrm{wt} / \mathrm{vol}$ $(0.25 \mathrm{mg} / \mathrm{mL})$, and far-UV CD spectra were recorded on a model 400 CD spectrophotometer (Aviv Biomedical, Inc., Lakewood, NJ, USA). To investigate the effects of $\mathrm{pH}$ on the self-assembly of the peptides, $50 \mathrm{mM}$ potassium chloride buffer ( $\mathrm{pH}$ 2), phosphate buffer ( $\mathrm{pH}$ 6-8), and borate buffer ( $\mathrm{pH}$ 9-10) were mixed with an equal volume of the peptide stock solutions, respectively. The software CDPro (Colorado State University, Fort Collins, CO, USA) was applied to estimate the secondary structure contents of the peptides. The peptide secondary structure fractions at various $\mathrm{pH}$ values were calculated by the SELCON3 method with comparison to the selected reference protein set (IBasis7 [SDP48]). For bFGF release experiment, freshly prepared bFGF solution was used to examine the possible secondary structure changes after $12 \mathrm{~h}$ of diffusion from $1 \% \mathrm{wt} / \mathrm{vol}$ (10 mg/mL) of P2 hydrogel. CD spectra were recorded between 195 and $250 \mathrm{~nm}$ at room temperature.

\section{Rheology measurement}

Time and dynamic frequency sweep rheology experiments $1 \% \mathrm{wt} / \mathrm{vol}$ of P2 hydrogel were performed at room temperature on a rheometer (HAAKE RheoStress 1; Thermo Fisher Scientific Inc., Waltham, MA, USA) with a cone and plate geometry system (cone diameter $2 \mathrm{~cm}$, angle $1^{\circ}$, truncation $51 \mu \mathrm{M}$ ). In brief, the P2 solution was mixed with an equal volume of phosphate buffer ( $\mathrm{pH} 7.2$ ), and an aliquot of $100 \mathrm{~mL}$ of the mixture was quickly placed on the plate. The time sweep experiment was performed at constant strain amplitude $(0.5 \%)$ and constant frequency $(1 \mathrm{~Hz})$ for $16 \mathrm{~min}$ to monitor the hydrogel storage modulus $\left(G^{\prime}\right)$ and loss modulus $\left(G^{\prime \prime}\right)$. Meanwhile, the hydrogel strength was measured via frequency sweep measurement over a range of frequencies of $10-0.01 \mathrm{~Hz}$ at fixed strain amplitude $(0.5 \%)$ after $30 \mathrm{~min}$ incubation with the phosphate buffer. 


\section{bFGF release experiment}

Various concentrations of $\mathrm{P} 2$ solution were mixed with the bFGF solution ( $\mathrm{pH}$ 7.2). The final concentration of bFGF was $5 \mu \mathrm{M}$. Then, $50 \mu \mathrm{L}$ of the mixtures was transferred into the wells of a 96-well plate before the formation of hydrogels. Subsequently, $350 \mu \mathrm{L}$ of the phosphate buffers was carefully pipetted into the hydrogels. The release experiments were carried out at room temperature, where $150 \mu \mathrm{L}$ of the supernatants was collected and replaced by the same volume of phosphate buffer at discrete time points. The collected supernatants were frozen until required and were then assayed for protein content by using Micro BCA Assay Kit (Thermo Fisher Scientific Inc.) with a standard curve of BSA $(0-40 \mu \mathrm{g} / \mathrm{mL})$ on a plate reader at an absorption wavelength of $562 \mathrm{~nm}$. These data allowed for the direct determination of released protein amounts as a function of time.

\section{Cell culture in hydrogel}

NIH-3T3 cell line (obtained from American Type Culture Collection [ATCC], Manassas, VA, USA) was cultured in Dulbecco's Modified Eagle's Medium (DMEM; Thermo Fisher Scientific) supplemented with 10\% FBS (Thermo Fisher Scientific). Prior to 3D culture, bFGF (Thermo Fisher Scientific) was added $(40 \mathrm{ng} / \mathrm{mL})$ into the media and cells were trypsinized and resuspended in bFGF containing media at a concentration of $5 \times 10^{5}$ cells $/ \mathrm{mL}$. The cell suspension was mixed with an equal volume of $\mathrm{P} 2$ stock solution to trigger the hydrogel formation ( $1 \% \mathrm{wt} / \mathrm{vol})$, and $40 \mu \mathrm{L}$ of the mixture was pipetted into each cell of the 96 -well plate. Then, $150 \mu \mathrm{L}$ of the bFGF $(20 \mathrm{ng} / \mathrm{mL})$ containing media was carefully added and followed by 30 min incubation in a $5 \% \mathrm{CO}_{2}$ incubator at $37^{\circ} \mathrm{C}$. After incubation, the upper bFGF containing media was replaced by bFGF-free media with FBS.

\section{Cell proliferation assay}

The Cell Counting Kit-8 (CCK-8; Sigma-Aldrich Inc., St. Louis, MO, USA) was used to analyze cell proliferation on days $0,2,4$, and 6 . For traditional two-dimensional (2D) petri dish culture and 3D hydrogel culture, NIH-3T3 cells were seeded at $5 \times 10^{3}$ cells/well and $10^{4}$ cells/well in 96-well plates, respectively. To perform the CCK-8 assay, each sample was carefully washed with phosphate buffer three times and incubated with $10 \mu \mathrm{L}$ of CCK-8 agent in $150 \mu \mathrm{L}$ of serum-free DMEM for $2 \mathrm{~h}$ at $37^{\circ} \mathrm{C}$. The absorbances at $450 \mathrm{~nm}$ were measured using a plate reader ( $\mu$ Quant; BioTek, Winooski, VT, USA). The 2D petri dishes without cells and 3D hydrogels without cells were subjected to the same process, to use as blanks. The data of both 2D culture samples and 3D hydrogel constructs were normalized to day 0 . Three parallel samples were analyzed in each group.

\section{Western blot analysis}

Cells were collected and lysed in cold radioimmunoprecipitation assay buffer (Thermo Fisher Scientific) containing protease inhibitor cocktail (Sigma-Aldrich). Cell lysates were boiled and subjected to $10 \%$ gradient sodium dodecyl sulfate polyacrylamide gel electrophoresis. The proteins were transferred from gels to a polyvinylidene difluoride (PVDF) membrane (Merck Millipore, Billerica, MA, USA). The membranes were blocked by immersion for $1 \mathrm{~h}$ at room temperature in 5\% nonfat skim milk/Tris-buffered saline and Tween 20 (TBST) and then incubated with primary antibodies against extracellular signal-related kinase (ERK) 1/2 (1:500; Abcam Inc., Cambridge, MA, USA), phospho-extracellular signalregulated kinase 1/2 (p-ERK1/2, 1:1,000; Cell Signaling Technology, Danvers, MA, USA), p27 (1:300; Thermo Fisher Scientific), cyclin D1(1:1,000; Cell Signaling Technology), and actin (1:1,000; Santa Cruz Biotechnology Inc., Santa Cruz, CA, USA) overnight at $4^{\circ} \mathrm{C}$. After washed in TBST, membranes were incubated with horseradish peroxidase-conjugated secondary antibodies (1:3,000; Thermo Fisher Scientific) for $1 \mathrm{~h}$ and then developed using an electrochemiluminescence blotting reagent (GE Healthcare, Piscataway, NJ, USA).

\section{Results and discussion Peptide self-assembly in aqueous solution}

TEM images of the peptide samples in aqueous solution are shown in Figure 2. P1 and P2 formed fibrillar assemblies with widths of $4.9 \pm 0.8 \mathrm{~nm}$ and $4.2 \pm 0.6 \mathrm{~nm}$, respectively, and lengths ranging from hundreds of nanometers to several micrometers in aqueous solution (Figure 2A and B). Meanwhile, $\mathrm{P} 3$ formed a globular aggregate with a diameter of $21.0 \pm 5.0 \mathrm{~nm}$ (Figure 2C). Both types of assemblies could be observed repeatedly in $\mathrm{P} 4$ solution, regardless of the peptide concentration. The nanofibers formed by $\mathrm{P} 4$ were wider $(6.0 \pm 1.3 \mathrm{~nm})$ but significantly shorter $(<1 \mu \mathrm{M})$ than those formed by P2 (Figure 2D). These results reveal the distinct innate self-assembly abilities of peptides with different sequence properties. DLS is a powerful tool for studying the ability to form nanostructures in solution. In this study, size distribution obtained by DLS experiments revealed the polymorphological size distributions of the nanostructures formed by the designed peptides (Figure 3). Combined with the TEM results, observation of a monodisperse population ranging in size from 670 to $6,000 \mathrm{~nm}$ for P1 and P2 indicated the dominant distribution of the nanofiber structures. The average size distribution of $\mathrm{P} 2$ was larger than that of P1. With 

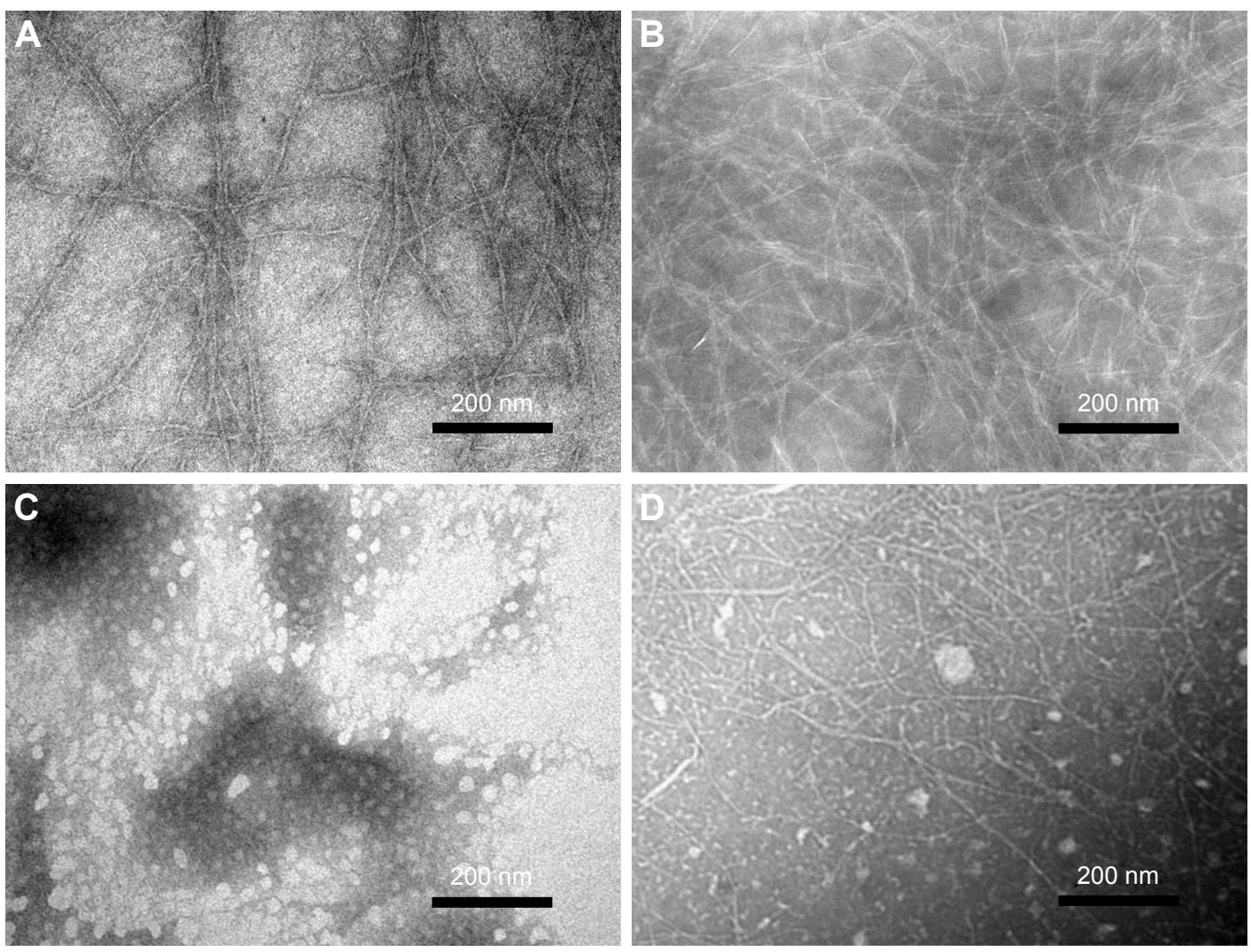

Figure 2 TEM images of the nanostructures formed from PI (A), P2 (B), P3 (C), and P4 (D) in Milli-Q water.

Note: All the peptides were diluted with Milli-Q water to $0.05 \% \mathrm{wt} / \mathrm{vol}(\sim 0.3 \mathrm{mM})$ and negatively stained with phosphotungstic acid before observation.

Abbreviations: PI, RADAGVGVRADAGVGV; P2, RLDLGVGVRLDLGVGV; P3, RARAGVGVDADAGVGV; P4, RLRLGVGVDLDLGVGV; TEM, transmission electron microscopy; wt/vol, weight/volume.

regard to $\mathrm{P} 3$, the population observed at a range of $10-23 \mathrm{~nm}$ suggested the formation of globular aggregates. Interestingly, two peaks with dimensions $\sim 10-50 \mathrm{~nm}$ and $400-1,000 \mathrm{~nm}$ could be found for $\mathrm{P} 4$. These peaks likely represent the two

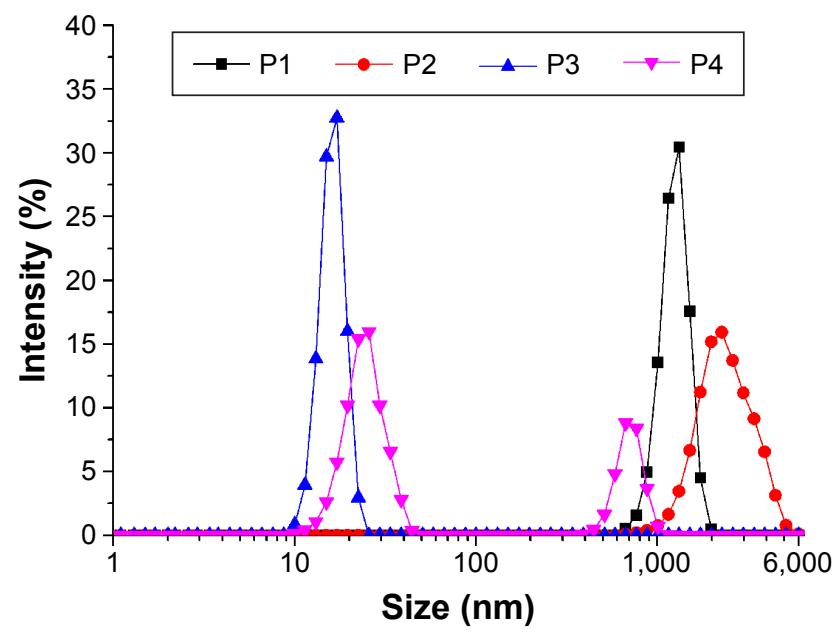

Figure 3 Size distribution of nanostructures formed by PI (A), P2 (B), P3 (C), and P4 (D) as determined by DLS measurements.

Notes: All the peptides were diluted to $0.05 \% \mathrm{wt} / \mathrm{vol}$ and sonicated for $15 \mathrm{~min}$ followed by standing at room temperature for $4 \mathrm{~h}$ before measurements.

Abbreviations: DLS, dynamic light scattering; PI, RADAGVGVRADAGVGV; P2, RLDLGVGVRLDLGVGV; P3, RARAGVGVDADAGVGV; P4, RLRLGVGVDLDLGVGV; wt/vol, weight/volume. populations of globular aggregates and nanofibers seen in Figure 2D, as the globular aggregates were generally smaller in diameter than the nanofibers. Data from the DLS experiments were in good accordance with the TEM results and were not influenced by $\mathrm{pH}$ changes (data not shown). It should be noted that the hydrodynamic diameter obtained from the DLS measurements was not equivalent to the actual structural diameter because nonspherical nanostructures such as vesicles, tubes, and fibers do not follow the Stokes-Einstein equation. ${ }^{36}$ In these cases, DLS can be used as a means for confirming the presence of nanostructures and for studying the relative size distributions of nanostructures. ${ }^{37}$

\section{Secondary structure of the designed peptides}

CD spectra of $0.125 \mathrm{mg} / \mathrm{mL}$ of peptides 1-4 in Milli-Q water are shown in Figure 4. A significant difference in secondary structure was seen among these peptides. The CD spectra of $\mathrm{P} 1$ and P2 demonstrated a sharp minimum at $\sim 215 \mathrm{~nm}$, indicating the predominant presence of $\beta$-sheets, which are crucial for peptide self-assembly and nanofiber formation. However, P3 displayed typical unordered structures with a minimum at $196 \mathrm{~nm}$. Interestingly, CD signals of P4 at 216 


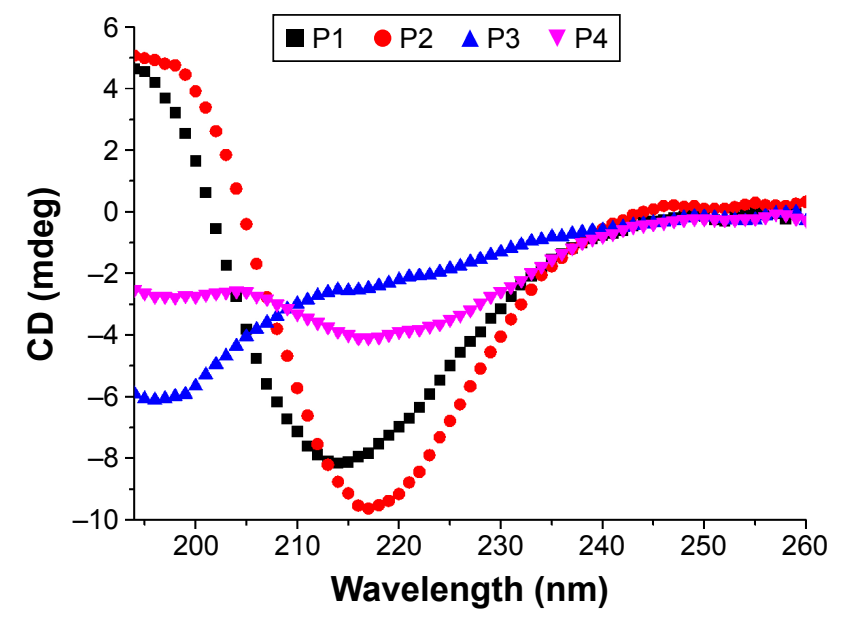

Figure 4 Secondary structures of the designed peptides $\mathrm{I}-4(0.125 \mathrm{mg} / \mathrm{mL})$ in Milli-Q water.

Notes: CD spectra of peptides I-4 were recorded at room temperature. The CD spectrum of $\mathrm{P} 2$ shows a typical $\beta$-sheet conformation, whereas $\mathrm{PI}$ and $\mathrm{P} 3$ display unordered structures. With regard to $P 4$, the $C D$ spectrum ranging from 200 to $220 \mathrm{~nm}$ reflects the coexistence of $\beta$-sheets and unordered structures.

Abbreviations: CD, circular dichroism; PI, RADAGVGVRADAGVGV; P2, RLDLGVGVRLDLGVGV; P3, RARAGVGVDADAGVGV; P4, RLRLGVGVDLDLGVGV.

and $\sim 196 \mathrm{~nm}$ indicated the presence of both $\beta$-sheets and unordered structural components. The $\beta$-sheet content of $\mathrm{P} 4$ was much lower than that of P1 and P2. According to CDPro software analysis, the $\beta$-sheet contents of $\mathrm{P} 1, \mathrm{P} 2$, and $\mathrm{P} 4$ were $34.6 \%, 40.8 \%$, and $26 \%$, respectively (regular $\beta$-strand [s (r)]; distorted $\beta$-strand [a partial but far-fromcomplete distortion of the regular $\beta$-strand, due to lack of some hydrogen bonds] [S (d)]) (Table 1). These results are in accordance with the TEM images, suggesting that higher $\beta$-sheet content and lower unordered structures are required for peptide self-assembly and nanofiber formation.

We also investigated the effects of $\mathrm{pH}$ on the selfassembly of the designed peptides. The results showed that the secondary structures of the peptides were not significantly altered at different $\mathrm{pH}$ levels (Figure 5). All the peptides had two positively charged arginines and two negatively charged aspartic acid residues at a neutral $\mathrm{pH}$. Arginine and

Table I Estimated structure fractions of the designed peptides in aqueous solution

\begin{tabular}{lllllll}
\hline Peptide & \multicolumn{7}{l}{ Secondary structure fractions (\%) } \\
\cline { 2 - 7 } & H (r) & H (d) & S (r) & S (d) & Turn & Unrd \\
\hline PI & 0.0 & 5.4 & 24.6 & 9.0 & 16.9 & 44.0 \\
P2 & I.I & 7.5 & 25.6 & 15.2 & 16.4 & 34.1 \\
P3 & 0.1 & 6.1 & 12.7 & 8.0 & 15.7 & 56.6 \\
P4 & 2.8 & 6.6 & 16.2 & 9.8 & 17.5 & 47.2 \\
\hline
\end{tabular}

Notes: $H(r)$, regular $\alpha$-helix; $H(d)$, distorted $\alpha$-helix; $S(r)$, regular $\beta$-strand; $S$ (d), distorted $\beta$-strand (a partial but far-from-complete distortion of the regular $\beta$-strand, due to lack of some hydrogen bonds); Turn, $\beta$-turn structure; Unrd, unordered structure.

Abbreviations: PI, RADAGVGVRADAGVGV; P2, RLDLGVGVRLDLGVGV; P3, RARAGVGVDADAGVGV; P4, RLRLGVGVDLDLGVGV. aspartic acid had a pKa of 12.5 and 3.9, respectively, in proteins. Similar to RADA16-I, only slight changes in the structural stability of the peptides were observed at all the $\mathrm{pH}$ values tested. With regard to $\mathrm{P} 1$ and $\mathrm{P} 2$, the difference in microdegree at $\sim 218 \mathrm{~nm}$ between each $\mathrm{pH}$ point was very small (Figure 5A and B), and all the spectra indicated a stable $\beta$-sheet structure. This implies that the overall $\beta$-sheet structure was not significantly altered at different $\mathrm{pH}$ values; even the negatively charged aspartic acid residues are neutralized at $\mathrm{pH}$ 2.0. This stability may be due to complementary electrostatic interactions and hydrogen bonds that are present when peptides self-assemble into $\beta$-sheet structures.

\section{Rheological properties of the hydrogel formed by $\mathrm{P} 2$}

To test the gel formation abilities of the peptides, P1 and P2 were subjected to rheological measurements. The results showed that the hydrogel formation process from $1 \% \mathrm{wt} / \mathrm{vol}$ of $\mathrm{P} 2$ took place in a few minutes once the $\mathrm{P} 2$ solution was mixed with an equal volume of phosphate buffer ( $\mathrm{pH}$ 7.2), whereas P1 remained viscous and failed to form a hydrogel. Time sweep and frequency sweep measurements were performed at room temperature to further study the elastic property of the hydrogel formed by P2. First, the mixture was treated with a constant strain amplitude of $0.5 \%$ at a constant frequency $(1 \mathrm{~Hz})$, after which the $G^{\prime}$ values of the P2 hydrogel increased over time, whereas the $G^{\prime \prime}$ values did not change with time (Figure 6A). The increasing $G^{\prime}$ value reflects the spontaneous growth of $\mathrm{P} 2$ nanofibers under selfassembly conditions. The frequency sweep measurements of the hydrogel displayed a frequency-independent modulus elastic response because the $G^{\prime}$ and $G^{\prime \prime}$ values were relatively constant and the $G^{\prime}$ values were much greater than zero (Figure 6B). Furthermore, we found that the $G^{\prime}$ values of P2 hydrogel increased to nearly 1,200 Pa after 1 month of incubation (data not shown). These results clearly demonstrate the gel-like properties and stability of the P2 hydrogel in aqueous solution.

\section{Effects of weak interactions on ionic complementary peptide self-assembly and hydrogel formation}

The ionic self-complementary peptide forms a $\beta$-sheet with a hydrophobic face and a hydrophilic face once it self-assembles into high-aspect-ratio nanofibers. The hydrophobic effect is the main driving force for peptide self-assembly, but this assembly is hindered by like-charge repulsion between the hydrophilic faces.$^{38}$ Hence, the peptides remain swollen until the hydrophobic effect dominates over this repulsion. In our 
A

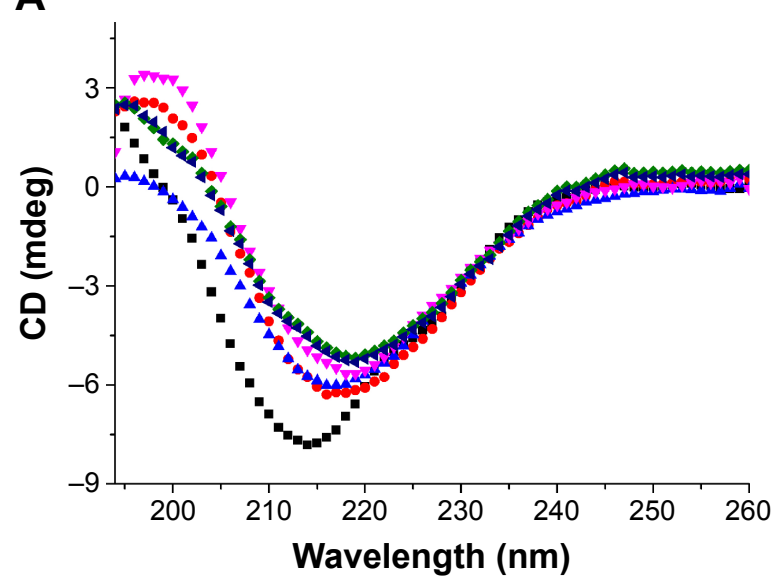

C

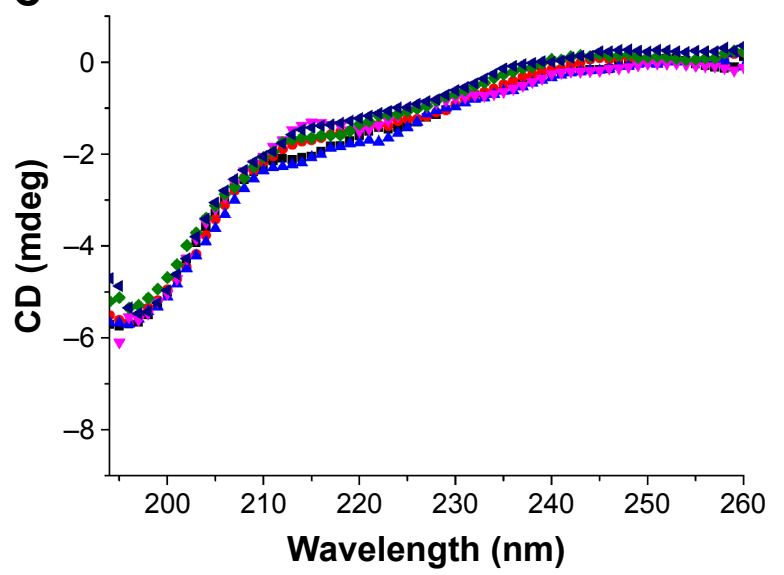

B

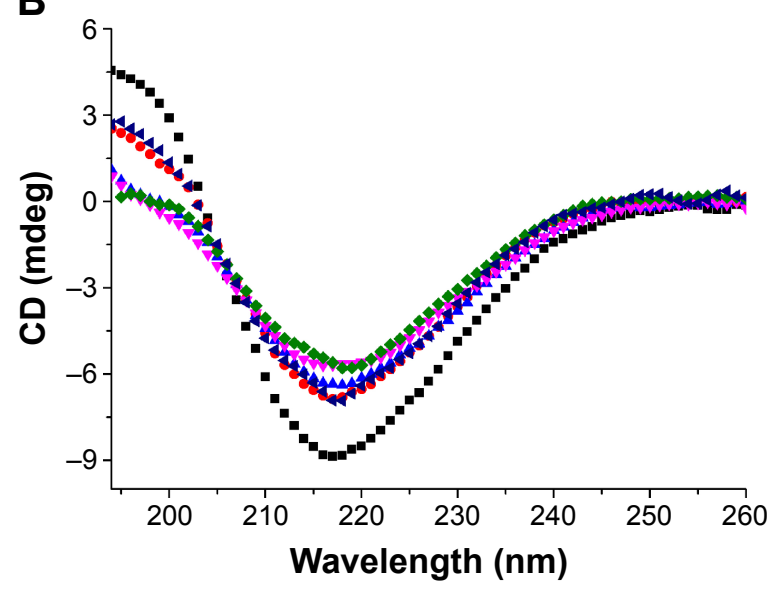

D

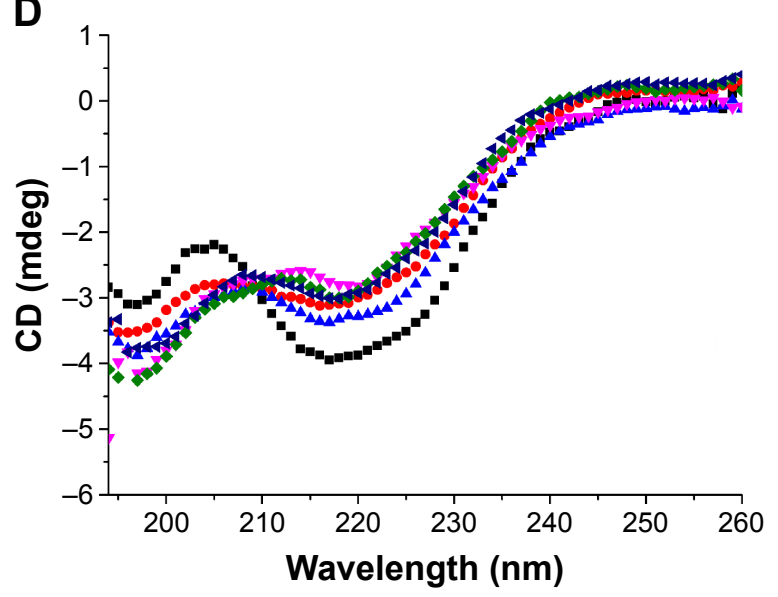

- $\mathrm{pH} 2 \bullet \mathrm{pH} 6 \Delta \mathrm{pH} 7 \nabla \mathrm{pH} 8 \diamond \mathrm{pH} 9 \triangleleft \mathrm{pH} 10$

Figure 5 CD spectra of PI (A), P2 (B), P3 (C), and P4 (D) in solutions from pH 2-10 at room temperature.

Note: The peptides were incubated in potassium chloride buffer $(\mathrm{pH} 2)$, phosphate buffer $(\mathrm{pH} 6-8)$, and borate buffer $(\mathrm{pH} 9-10)$, respectively, to give a final concentration of $0.125 \mathrm{mg} / \mathrm{mL}$.

Abbreviations: CD, circular dichroism; PI, RADAGVGVRADAGVGV; P2, RLDLGVGVRLDLGVGV; P3, RARAGVGVDADAGVGV; P4, RLRLGVGVDLDLGVGV.

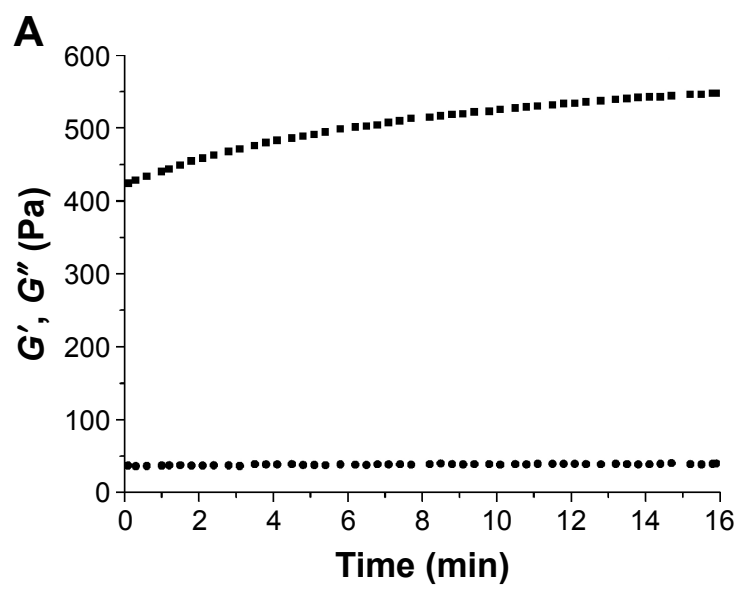

B

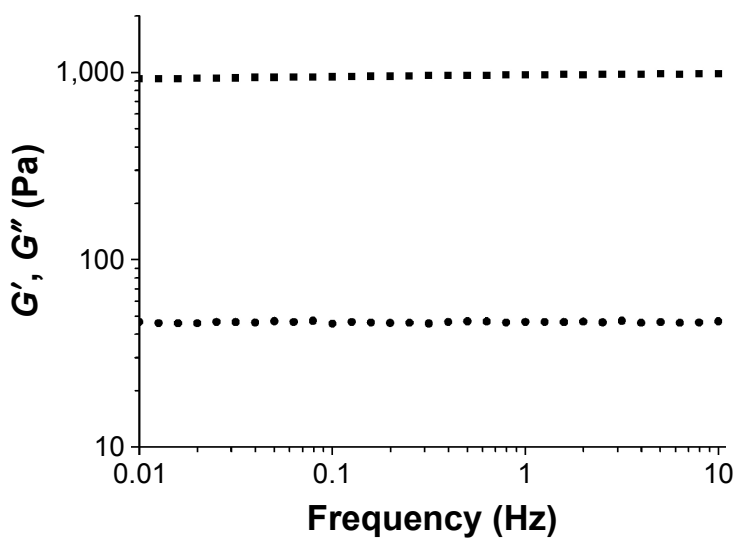

$\square \mathrm{G}^{\prime} \bullet \mathrm{G}^{\prime \prime}$

Figure 6 Rheology measurements of the hydrogel formed by P2 at I\% wt/vol.

Notes: Time sweep $(\mathbf{A})$ and frequency sweep $(\mathbf{B})$ for the $\mathrm{P} 2$ hydrogel. The hydrogel was made by mixing with an equal volume of phosphate buffer ( $\mathrm{pH} 7.2$ ), and the frequency sweep measurement was performed after a 30-min incubation at room temperature.

Abbreviations: $G^{\prime}$, storage modulus; $G^{\prime \prime}$, loss modulus; P2, RLDLGVGVRLDLGVGV; wt/vol, weight/volume. 
case, with regard to $\mathrm{P} 1$, the incorporation of two GVGV repeats into RADA16-I resulted in an increase in hydrophobic effects and a decrease in like-charge repulsion. P1 could undergo spontaneous assembly into well-defined nanofibers with an internal $\beta$-sheet structure during aggregation (Figure 2A). The secondary P1 structure was quite stable at various $\mathrm{pH}$ values; however, it was viscous and failed to form a hydrogel even though its net charge was almost zero in phosphate buffer ( $\mathrm{pH} 7.2$; data not shown). It has been reported that bringing the peptide net charge to zero should eliminate the kinetic barrier to assembly and facilitate gelation., ${ }^{76,38}$ This contradiction can be explained by the increasing peptide chain entropy, because incorporating glycine increases the entropic cost of constraining the peptide backbone during $\beta$-sheet formation. ${ }^{31}$ Peptide self-assembly is favored by the hydrophobic effect but opposed by peptide chain entropy since the assembly events dramatically decrease the number of accessible conformations. Hence, we propose that the balance among electrostatic repulsion, chain entropy, and hydrophobic effects determine the molecular state and assembly of the designed peptides and even formation of the hydrogel. To further validate this hypothesis, the side chain hydrophobicity was increased by substitution of As with Ls (P2). The $\beta$-sheet content of P2 was increased (Figure 4) compared with that of P1, and hydrogel formation occurred when charges on the arginine and aspartic acid side chains were screened in phosphate buffer (Figure 6). This can be explained by the fact that the side chain hydrophobicity of P2 is larger than that of $\mathrm{P} 1$. As a result, increasing the hydrophobicity level leads to hydrogel formation because formation and the associated mechanical properties are influenced by the level of peptide hydrophobicity. ${ }^{39,40}$ This phenomenon can also be seen in P3 and P4. The increasing hydrophobicity of the side chain indeed increased the driving force for assembly, although only partial P4 molecules tended to adopt the $\beta$-sheet structure and subsequently self-assemble into fiber-like microstructures. In addition, in some cases, the intramolecular electrostatic interaction played a role in the folding and self-assembly of the peptides. Swapping an arginine with an aspartic acid residue results in a change in the charge arrangement (P3), that is, from a positive-negative-positive-negative pattern to a positive-positive-negative-negative pattern. For example, at an intermediate $\mathrm{pH}, \mathrm{P} 3$ appeared to have a stronger intramolecular electrostatic interaction between positively charged arginine residues and negatively charged aspartic acid residues than $\mathrm{P} 1$. The unique characteristic of glycine lacking a side chain allowed the GVGV sequences to twist without steric hindrance. Consequently, the P3 molecule may be able to bend to form a hairpin-like structure driven by the intramolecular electrostatic interaction. The resulting bent molecules may continue to grow into larger globular assemblies (Figure 2D).

\section{In vitro release of bFGF through the hydrogel}

Self-assembling peptides have been increasingly studied as 3D matrices for numerous biomedical applications, including tissue engineering and controlled drug/protein release. The physicochemical properties of these nanofibers may affect not only the release rate but also protein conformation and function. ${ }^{41}$ Self-assembling peptides with different amino acid sequences may significantly affect protein release. ${ }^{18}$ To test this theory, bFGF was used as a model molecule and was encapsulated within the P2 hydrogel. bFGF is a recognized mitogen for multiple cell types, including fibroblasts, and it also promotes cell proliferation by inducing progression of the cell cycle from the G0/G1 to S phase. ${ }^{42}$ Its release profile through $\mathrm{P} 2$ hydrogels of different peptide nanofiber densities is presented in Figure 7A. The hydrogels consisted of self-assembling P2 with concentrations of 0.7 , $1.0,1.5$, and $2.0 \mathrm{wt} / \mathrm{vol} \%$. Two distinct stages, including the initial burst stage and plateau stage, were observed. With regard to the $1 \% \mathrm{wt} / \mathrm{vol}$ concentration of $\mathrm{P} 2, \sim 36 \%$ of $\mathrm{bFGF}$ was released through the hydrogel in the first $5 \mathrm{~h}$, although the release decreased over time and seemed to plateau after $22 \mathrm{~h}$. The overall release rate increased concomitant with an increase in peptide concentration, which also led to a higher nanofiber density that hindered the release of bFGF molecules. These results show that the P2 hydrogel can be used as a potential carrier for protein release; the release of bFGF could be tuned by adjusting the concentration of the P2 hydrogel and the growth factors encapsulated within. The interactions between proteins and between proteins and peptides and their assemblies may lead to structural disruptions during peptide self-assembly and nanofiber formation and during the release process. Structural disruptions in proteins often result in aggregation and decreased biological activity. Far-UV light CD spectroscopy was used to obtain further insights into the conformational state of the released protein. The results showed that the secondary structure of native bFGF was quite similar to that reported earlier ${ }^{43}$ (Figure 7B). The secondary structure of the released bFGF closely resembled that of native bFGF, suggesting that the interaction of proteins with the nanofiber hydrogel did not induce changes in the secondary structure, which is crucial for maintaining the activity of bFGF. 

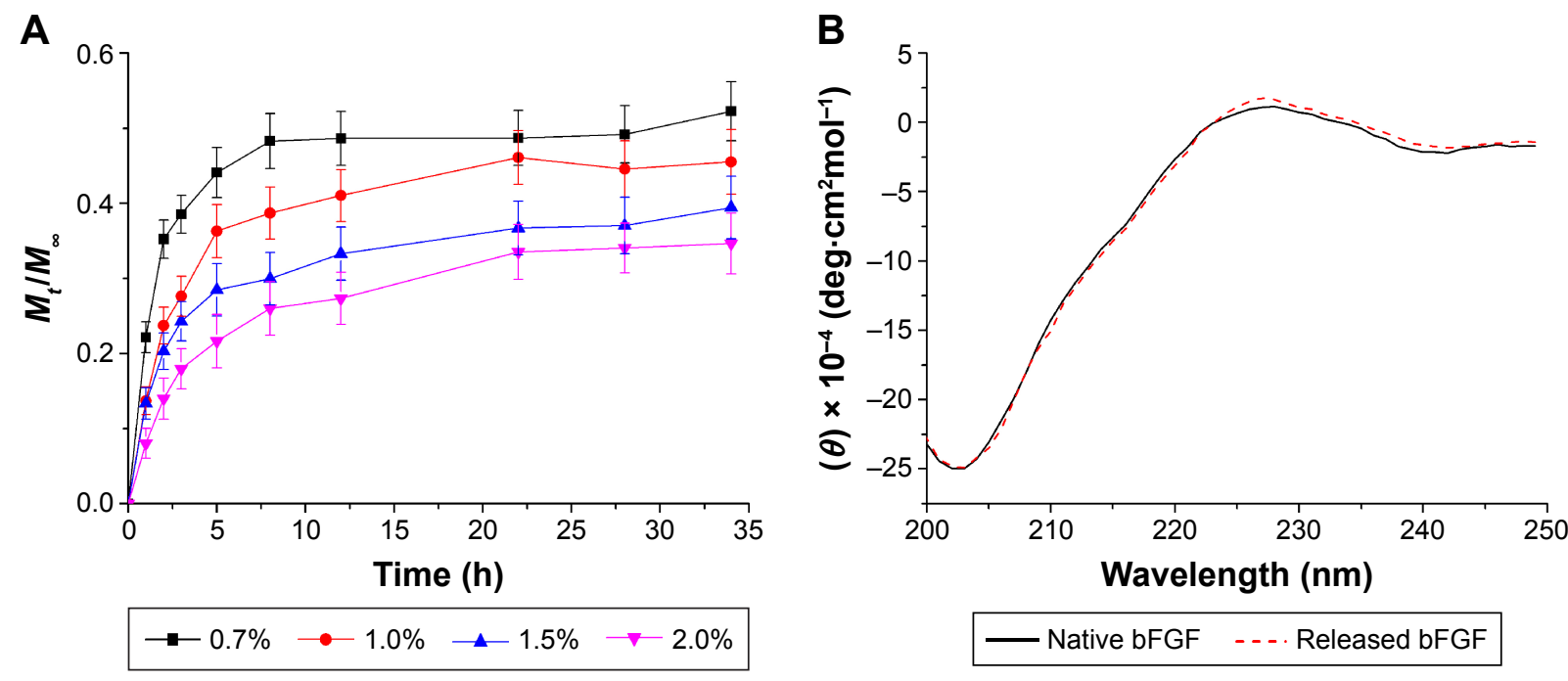

Figure 7 In vitro release of bFGF through the self-assembling P2 hydrogel.

Notes: (A) Release profiles for bFGF through P2 hydrogels of different peptide nanofiber densities. The P2 concentrations are $0.7,1.0,1.5$, and $2.0 \mathrm{wt} / \mathrm{vol} \%$. Release experiments were performed in PBS ( $\mathrm{pH}$ 7.4) at room temperature. Data points represent the average of five samples. (B) CD spectra of native and released bFGF solutions through the hydrogel $(1 \% \mathrm{wt} / \mathrm{vol})$ in PBS $\left(\mathrm{pH}\right.$ 7.4). Spectra were recorded at room temperature. Data points represent the average of four samples. $M_{t}$ and $M_{\infty}$ are the cumulative mass of the diffusing compound released from the hydrogel after $t$ and infinite time $(\infty)$, respectively.

Abbreviations: bFGF, basic fibroblast growth factor; CD, circular dichroism; P2, RLDLGVGVRLDLGVGV; PBS, phosphate-buffered saline; wt/vol, weight/volume.

\section{Encapsulated bFGF promotes the proliferation of $\mathrm{NIH}-3 \mathrm{~T} 3$ cells}

Next, we used the NIH-3T3 mouse embryo fibroblast cell line to determine if the released bFGF could elicit its biological functions in vitro. To determine the effects of controlled bFGF release on cell proliferation, cells were subjected to traditional 2D culture or were embedded within the $\mathrm{P} 2$ hydrogel with or without $20 \mathrm{ng} / \mathrm{mL}$ bFGF. As shown in Figure 8B, the cells survived and continued to divide in the P2 hydrogel during the course of the experiment. The NIH-3T3 cells began to aggregate into clusters without losing their spherical morphology after 4 days of culture. To evaluate the cell proliferation in 3D hydrogel and 2D culture, a CCK-8 assay was used to test the metabolic activity on days $0,2,4$, and 6 . The results showed that, compared with day 0 , cells embedded in P2 hydrogel alone showed 1.6-fold proliferation on
A

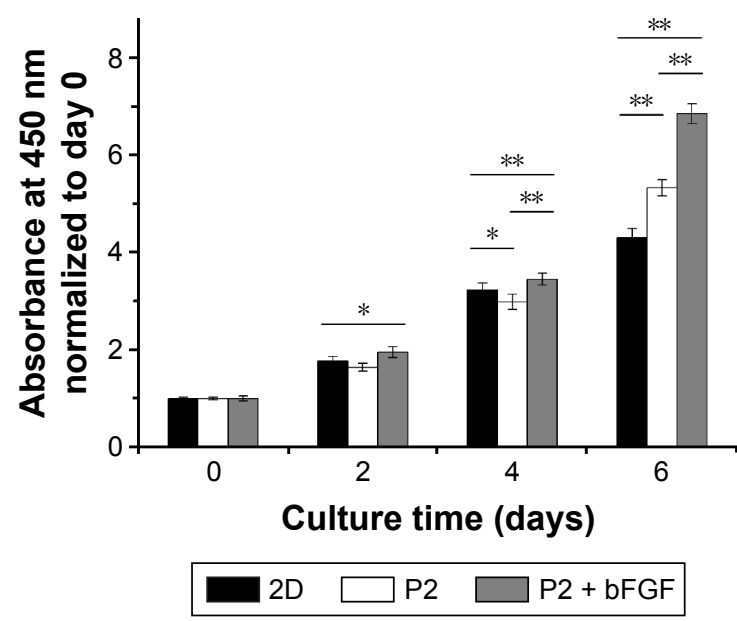

B

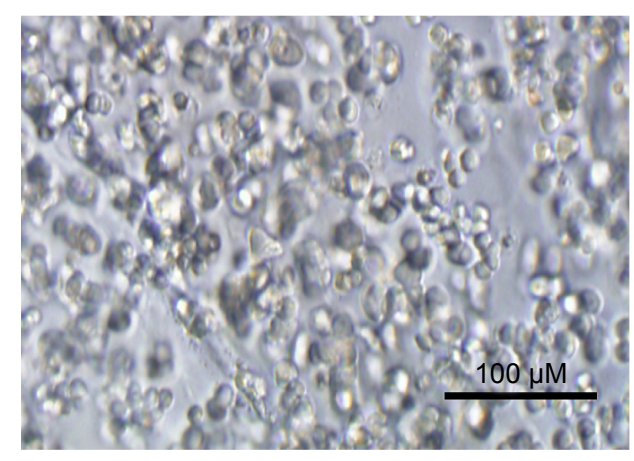

Figure 8 Effect of hydrogel-released bFGF on NIH-3T3 cell proliferation.

Notes: (A) Proliferation curve of cultured NIH-3T3 cells as determined by the CCK-8 test. The P2 hydrogel alone and a traditional 2D petri dish were used as the controls. The data from both 2D culture samples and $3 \mathrm{D}$ hydrogel constructs were normalized to day 0 . One asterisk $(*)$ indicates a $P$-value smaller than $0.05(P<0.05)$. Two asterisks (**) indicate a $P$-value smaller than $0.01(P<0.01)$. Data points represent the average of three samples. (B) Optical micrograph of NIH-3T3 cells embedded in the bFGFreleasing hydrogel after 4 days of culture.

Abbreviations: 2D, two-dimensional; 3D, three-dimensional; bFGF, basic fibroblast growth factor; CCK-8, Cell Counting Kit-8; P2, RLDLGVGVRLDLGVGV. 
day 2, 3.0-fold proliferation on day 4, and 5.3-fold proliferation on day 6 , whereas cells in hydrogel/bFGF constructs showed 2.0-fold proliferation on day 2, 3.5-fold proliferation on day 4 , and 6.9-fold proliferation on day 6 . The number of cells cultured on the $2 \mathrm{D}$ petri dish on days 2,4 , and 6 was $1.8-$, 3.2-, and 4.3-fold greater than that at day 0 . The proliferation rate was highest in the hydrogel/bFGF constructs and was significantly higher when cultured in P2 hydrogel compared to the $2 \mathrm{D}$ petri dish (Figure $8 \mathrm{~A}$ ). These data confirm that the encapsulated bFGF remained biologically active after release. Considering that there was no addition of bFGF during the experiment, encapsulation within the P2 hydrogel led to a continuous release of biologically active bFGF. These data collectively suggest that encapsulation within the P2 hydrogel does not change the ability of bFGF to stimulate the proliferation of NIH-3T3 cells and the biological activity of bFGF can be maintained when encapsulated within the hydrogel.

\section{Encapsulated bFGF can activate downstream signaling pathways}

Our data show that the proliferation of NIH-3T3 cells was promoted by encapsulated bFGF and suggest that encapsulated bFGF can be released from the hydrogel into the local milieu with biological activity. To determine if the encapsulated bFGF can activate downstream signaling pathways, ERK, p27, and cyclin D1 levels were analyzed. ERK is a subfamily member of mitogen-activated protein kinases (MAPKs), which have been implicated in diverse cellular processes, including proliferation, differentiation, and migration. ${ }^{44}$ Once activated, ERK translocates from the cytoplasm to the nucleus, where it phosphorylates various nuclear targets, resulting in cell proliferation. ${ }^{45,46} \mathrm{We}$ found that the encapsulated bFGF led to an increased p-ERK/ERK ratio after 2 days of culture (Figure 9A). Interestingly, the $\mathrm{p}-\mathrm{ERK} / \mathrm{ERK}$ ratios in the $\mathrm{P} 2$ hydrogel culture groups were significantly higher than those in the $2 \mathrm{D}$ culture groups. These results are in accordance with data from the CCK- 8 analyses and can be explained by the fact that the P2 hydrogel has 3D nanofiber structures similar to that of the natural ECM. Thus, the hydrogel supports attachment of NIH-3T3 cells and enhances the ECM-cell interactions, resulting in stimulation of cell proliferation. These findings indicate that combined treatment with $\mathrm{P} 2$ hydrogel and bFGF might be superior to either one alone for improving NIH-3T3 cell proliferation.
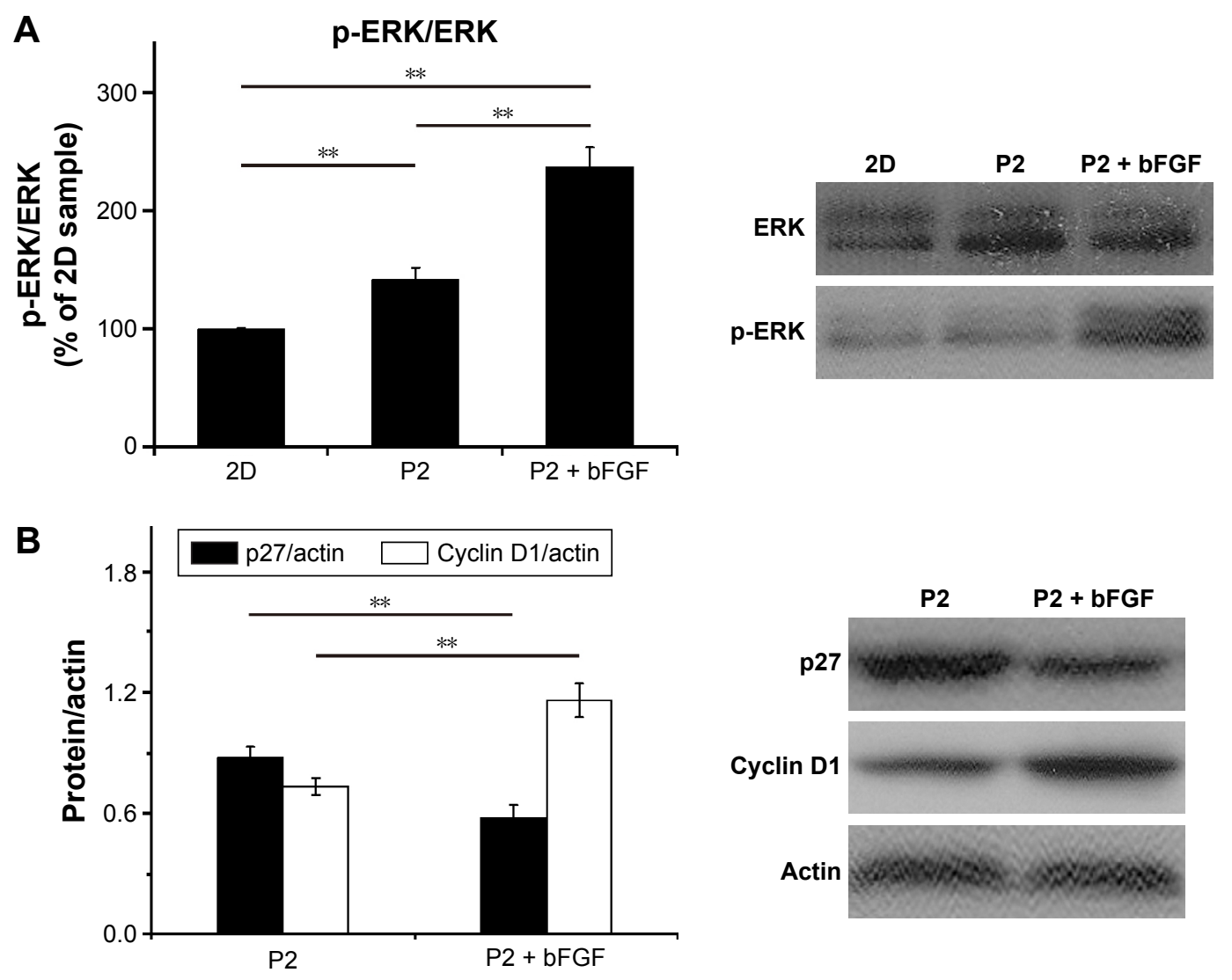

Figure 9 Growth factor signaling after bFGF was encapsulated within the P2 hydrogel.

Notes: Western blot analysis of ERK, p-ERK, p27, and cyclin DI after 2 days of culture and quantitative analysis of the protein levels. Two asterisks (**) indicate a $P$-value smaller than $0.01(P<0.01)$.

Abbreviations: 2D, two-dimensional; bFGF, basic fibroblast growth factor; ERK, extracellular signal-regulated kinase; p-ERK, phospho-extracellular signal-regulated kinase; P2, RLDLGVGVRLDLGVGV. 
Cyclin D1 is a protein required for progression through the G1 phase of the cell cycle, and p27 is a negative regulator of the cell cycle that restricts the G1/S phase transition and inhibits cell proliferation. ${ }^{47}$ ERK activity contributes to the induction of cyclin D1 and downregulation of p27.45,48 Here, we examined the protein levels of cyclin D1 and p27 and found that encapsulated bFGF led to increased levels of cyclin D1 and reduced levels of p27 in NIH-3T3 cells (Figure 9B), indicating that growth factor signaling pathways were not disrupted by hydrogel encapsulation. Together, these experiments show that encapsulated and released bFGF is biologically active and can activate downstream signaling pathways.

\section{Conclusion}

In this study, the GVGV tetrapeptide, an elastin-derived sequence, was incorporated into the RADA16-I sequence to evaluate the effects of weak interactions on the folding and self-assembly of the peptide. The results demonstrated that the balance among the hydrophobic effects, intermolecular electrostatic interactions, and chain entropy determined the molecular state and assembly of the designed peptides. The intramolecular electrostatic interaction also contributed to the secondary structure formation. Among the four designed peptides, P2 could undergo a structural transition and form an elastic hydrogel when exposed to phosphate buffer. Encapsulation of bFGF resulted in a low, steady release from the hydrogel into the local milieu in a biologically active form, and the release rate was related to the peptide concentration. The self-assembly of the peptide and encapsulation within the hydrogel did not induce changes in the secondary structure of bFGF. In addition, the released bFGF promoted the proliferation of NIH-3T3 cells and activated downstream signaling pathways, such as ERK pathways. Taken together, our data suggest that the P2 hydrogel has the potential to be used in fine-tune growth factor delivery.

\section{Acknowledgments}

We thank Accdon for its linguistic assistance during the preparation of this manuscript. This work was supported by the National Natural Science Foundation of China (31360232), the Key Project of Guizhou Province Science and Technology Department (Qian ke he J zi LKZ[2013]01), and the Natural Science Research Project of Education Department of Guizhou Province (Qian jiao he KY zi [2015]418).

\section{Disclosure}

The authors report no conflicts of interest in this work.

\section{References}

1. Chen CL, Rosi NL. Peptide-based methods for the preparation of nanostructured inorganic materials. Angew Chem Int Ed. 2010;49(11): 1924-1942.

2. Adler-Abramovich L, Aronov D, Beker P, et al. Self-assembled arrays of peptide nanotubes by vapour deposition. Nat Nanotechnol. 2009; 4(12):849-854.

3. Wang M, Du L, Wu X, Xiong S, Chu PK. Charged diphenylalanine nanotubes and controlled hierarchical self-assembly. ACS Nano. 2011;5(6):4448-4454.

4. Chen Y, Tang C, Zhang J, Gong M, Su B, Qiu F. Self-assembling surfactant-like peptide A6K as potential delivery system for hydrophobic drugs. Int J Nanomedicine. 2015;10:847.

5. Schneider JP, Pochan DJ, Ozbas B, Rajagopal K, Pakstis L, Kretsinger J. Responsive hydrogels from the intramolecular folding and selfassembly of a designed peptide. J Am Chem Soc. 2002;124(50): 15030-15037.

6. Dong H, Paramonov SE, Aulisa L, Bakota EL, Hartgerink JD. Selfassembly of multidomain peptides: balancing molecular frustration controls conformation and nanostructure. J Am Chem Soc. 2007;129(41): 12468-12472.

7. Liu Y, Yang Y, Wang C, Zhao X. Stimuli-responsive self-assembling peptide made from antibacterial peptide. Nanoscale. 2013;5(14): 6413-6421.

8. Zhang S, Holmes T, Lockshin C, Rich A. Spontaneous assembly of a self-complementary oligopeptide to form a stable macroscopic membrane. Proc Natl Acad Sci U S A. 1993;90(8):3334-3338.

9. van Eldijk MB, McGann CL, Kiick KL, van Hest JC. Elastomeric polypeptides. Top Curr Chem. 2012;310:71-116.

10. Xia X-X, Xu Q, Hu X, Qin G, Kaplan DL. Tunable self-assembly of genetically engineered silk-elastin-like protein polymers. Biomacromolecules. 2011;12(11):3844-3850.

11. Um SH, Lee JB, Park N, Kwon SY, Umbach CC, Luo D. Enzyme-catalysed assembly of DNA hydrogel. Nat Mater. 2006;5(10):797-801.

12. Liao SW, Yu T-B, Guan Z. De novo design of saccharide-peptide hydrogels as synthetic scaffolds for tailored cell responses. J Am Chem Soc. 2009;131(48):17638-17646.

13. Conn CE, Drummond CJ. Nanostructured bicontinuous cubic lipid selfassembly materials as matrices for protein encapsulation. Soft Matter. 2013;9(13):3449-3464.

14. Zhang L, Chan JM, Gu FX, et al. Self-assembled lipid-polymer hybrid nanoparticles: a robust drug delivery platform. ACS Nano. 2008; 2(8):1696-1702.

15. O'Leary LER, Fallas JA, Bakota EL, Kang MK, Hartgerink JD. Multihierarchical self-assembly of a collagen mimetic peptide from triple helix to nanofibre and hydrogel. Nat Chem. 2011;3:821-828.

16. Hartgerink JD, Beniash E, Stupp SI. Peptide-amphiphile nanofibers: a versatile scaffold for the preparation of self-assembling materials. Proc Natl Acad Sci U S A. 2002;99(8):5133-5138.

17. Wong VW, Rustad KC, Galvez MG, et al. Engineered pullulan-collagen composite dermal hydrogels improve early cutaneous wound healing. Tissue Eng Part A. 2011;17(5-6):631-644.

18. Gelain F, Unsworth LD, Zhang S. Slow and sustained release of active cytokines from self-assembling peptide scaffolds. J Control Release. 2010;145(3):231-239.

19. Lindsey S, Piatt JH, Worthington P, et al. Beta hairpin peptide hydrogels as an injectable solid vehicle for neurotrophic growth factor delivery. Biomacromolecules. 2015;16(9):2672-2683.

20. Ellis-Behnke RG, Liang Y-X, You S-W, et al. Nano neuro knitting: peptide nanofiber scaffold for brain repair and axon regeneration with functional return of vision. Proc Natl Acad Sci U S A. 2006;103(13): 5054-5059.

21. Wang Z, Lin M, Xie Q, et al. Electrospun silk fibroin/poly (lactideco- $\varepsilon$-caprolactone) nanofibrous scaffolds for bone regeneration. Int J Nanomedicine. 2016;11:1483.

22. Tysseling-Mattiace VM, Sahni V, Niece KL, et al. Self-assembling nanofibers inhibit glial scar formation and promote axon elongation after spinal cord injury. J Neurosci. 2008;28(14):3814-3823. 
23. Loo Y, Wong Y-C, Cai EZ, et al. Ultrashort peptide nanofibrous hydrogels for the acceleration of healing of burn wounds. Biomaterials. 2014;35(17):4805-4814.

24. Zhang S. Designer self-assembling peptide nanofiber scaffolds for study of 3-D cell biology and beyond. Adv Cancer Res. 2008;99:335-362.

25. Silva GA, Czeisler C, Niece KL, et al. Selective differentiation of neural progenitor cells by high-epitope density nanofibers. Science. 2004; 303(5662):1352-1355.

26. Lakshmanan A, Zhang S, Hauser CA. Short self-assembling peptides as building blocks for modern nanodevices. Trends Biotechnol. 2012; 30(3):155-165.

27. Smith AM, Banwell EF, Edwards WR, Pandya MJ, Woolfson DN. Engineering increased stability into self-assembled protein fibers. $A d v$ Funct Mater. 2006;16(8):1022-1030.

28. Mart RJ, Osborne RD, Stevens MM, Ulijn RV. Peptide-based stimuliresponsive biomaterials. Soft Matter. 2006;2:822-835.

29. Gelain F, Bottai D, Vescovi A, Zhang S. Designer self-assembling peptide nanofiber scaffolds for adult mouse neural stem cell 3-dimensional cultures. PLoS One. 2006;1:e119.

30. Vrhovski B, Weiss AS. Biochemistry of tropoelastin. Eur J Biochem. 1998;258(1):1-18.

31. Rauscher S, Baud S, Miao M, Keeley FW, Pomès R. Proline and glycine control protein self-organization into elastomeric or amyloid fibrils. Structure. 2006;14(11):1667-1676.

32. Lee J, Macosko CW, Urry DW. Elastomeric polypentapeptides cross-linked into matrixes and fibers. Biomacromolecules. 2001;2(1): 170-179.

33. Costa RR, Custódio CA, Testera AM, et al. Stimuli-responsive thin coatings using elastin-like polymers for biomedical applications. $A d v$ Funct Mater. 2009;19(20):3210-3218.

34. Anumolu R, Gustafson JA, Magda JJ, Cappello J, Ghandehari H, Pease LF 3rd. Fabrication of highly uniform nanoparticles from recombinant silk-elastin-like protein polymers for therapeutic agent delivery. ACS Nano. 2011;5(7):5374-5382.

35. Cappello J, Crissman J, Dorman M, et al. Genetic engineering of structural protein polymers. Biotechnol Prog. 1990;6(3):198-202.

36. von Maltzahn G, Vauthey S, Santoso S, Zhang S. Positively charged surfactant-like peptides self-assemble into nanostructures. Langmuir. 2003;19(10):4332-4337.
37. Wu C, Li M, Kwan SCM, Liu GJ. Laser light scattering characterization of a novel polymer nanofiber. Macromolecules. 1998;31(21): 7553-7554.

38. Zhang S, Lockshin C, Cook R, Rich A. Unusually stable $\beta$-sheet formation in an ionic self-complementary oligopeptide. Biopolymers. 1994; 34(5):663-672.

39. Caplan MR, Moore PN, Zhang S, Kamm RD, Lauffenburger DA. Selfassembly of a $\beta$-sheet protein governed by relief of electrostatic repulsion relative to van der Waals attraction. Biomacromolecules. 2000; 1(4):627-631.

40. Leon EJ, Verma N, Zhang S, Lauffenburger DA, Kamm RD. Mechanical properties of a self-assembling oligopeptide matrix. J Biomater Sci Polym Ed. 1998;9(3):297-312.

41. Koutsopoulos S, Unsworth LD, Nagai Y, Zhang S. Controlled release of functional proteins through designer self-assembling peptide nanofiber hydrogel scaffold. Proc Natl Acad Sci U S A. 2009;106(12): 4623-4628.

42. Jones SM, Kazlauskas A. Growth-factor-dependent mitogenesis requires two distinct phases of signalling. Nat Cell Biol. 2001;3(2):165-172.

43. Huang Z, Ye C, Liu Z, et al. Solid-phase N-terminus PEGylation of recombinant human fibroblast growth factor 2 on heparin-sepharose column. Bioconjug Chem. 2012;23(4):740-750.

44. Wetzker R, Böhmer F-D. Transactivation joins multiple tracks to the ERK/MAPK cascade. Nat Rev Mol Cell Biol. 2003;4(8):651-657.

45. Chambard J-C, Lefloch R, Pouysségur J, Lenormand P. ERK implication in cell cycle regulation. Biochim Biophys Acta. 2007;1773(8): 1299-1310.

46. Moreno-Layseca P, Streuli CH. Signalling pathways linking integrins with cell cycle progression. Matrix Biol. 2014;34:144-153.

47. Malumbres M, Barbacid M. Cell cycle, CDKs and cancer: a changing paradigm. Nat Rev Cancer. 2009;9(3):153-166.

48. Villanueva J, Yung Y, Walker JL, Assoian RK. ERK activity and G1 phase progression: identifying dispensable versus essential activities and primary versus secondary targets. Mol Biol Cell. 2007;18(4): 1457-1463.
International Journal of Nanomedicine

\section{Publish your work in this journal}

The International Journal of Nanomedicine is an international, peerreviewed journal focusing on the application of nanotechnology in diagnostics, therapeutics, and drug delivery systems throughout the biomedical field. This journal is indexed on PubMed Central, MedLine, CAS, SciSearch $®$, Current Contents ${ }^{\circledR} /$ Clinical Medicine,

\section{Dovepress}

Journal Citation Reports/Science Edition, EMBase, Scopus and the Elsevier Bibliographic databases. The manuscript management system is completely online and includes a very quick and fair peer-review system, which is all easy to use. Visit http://www.dovepress.com/ testimonials.php to read real quotes from published authors. 